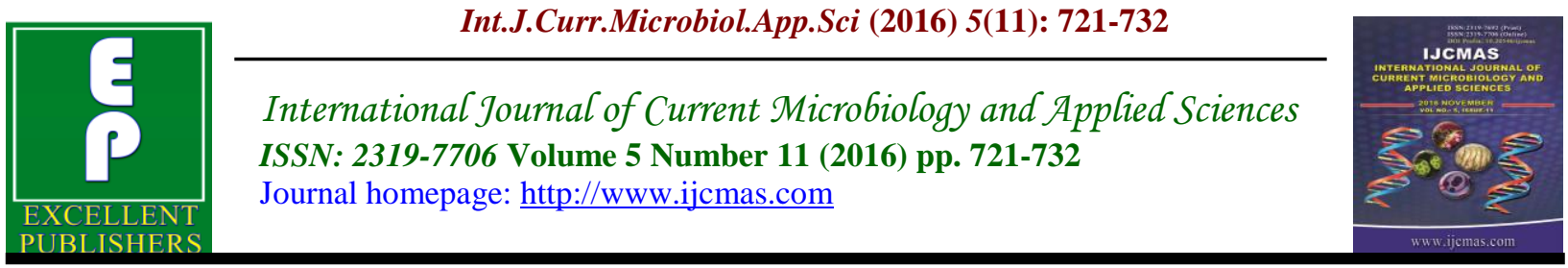

Review Article

http://dx.doi.org/10.20546/ijcmas.2016.511.083

\title{
Lactulose: Significance in Milk and Milk Products
}

\author{
Sonali L. Parekh*, Smitha Balakrishnan, Subrota Hati and K. D. Aparnathi \\ Department of Dairy Chemistry, SMC College of Dairy Science, \\ Anand Agricultural University, Anand-388110, India \\ *Corresponding author
}

\section{A B S T R A C T}

\section{Keywords}

Epimer, Isomerization, Prebiotic, Endotoxemia.

Article Info

Accepted:

26 October 2016

Available Online:

10 November 2016
Many kinds of lactose derivatives can be obtained using various methods, including epimerization, oxidation and reduction. Lactulose is not only utilized as an indicator substance for milk heat treatment but it also represents one of the most valuable lactose derivatives with therapeutical applications dating back to the middle of the last century. Lactulose is a non-caloric, synthetic disaccharide formed from one molecule each of fructose and galactose. Technologically, lactulose can be produced by the isomerization of lactose molecule in which a new ketose sugar from aldose by regrouping the glucose residue to the fructose molecule. It is widely used in pharmaceutical and food industries because of its beneficial effects on human health. In particular, lactulose, galactooligosaccharide and lactitol are used in foodstuffs and pharmaceuticals, and new lactose derivatives such as epilactose and tagatose have also recently received attention.

\section{Introduction}

Lactose, a unique disaccharide, occurring exclusively in the mammalian milk plays an important role in nutrition. Most of the lactose that is manufactured on an industrial scale is produced from whey derived from the production of cheese, casein or paneer using crystallization and purification technologies. Lactose can be converted to various derivatives like lactitol, lactobionic acid, galacto-oligosaccharide, epilactose etc., using laboratory or industrial processes. They are widely used in food and in pharmaceutical fields due to their special characteristics. Lactulose is a derivative of lactose obtained by Isomerization of glucose moiety of lactose to fructose (Claeys et al., 2001).

\section{Chemistry and Properties of Lactulose}

Lactulose (4-O- $\beta$-D-Galactopyranosyl-Dfructofuranose), the isomerized lactose, is a disaccharide consisting of galactose and fructose with a molecular weight 342 . It belongs to the few carbohydrates other than lactose that play an important role in the dairy fields (Gaenzle et al., 2008). Although Lactulose was first systhesized in 1929 (Montgomery and Hudson, 1930) physically, its significance was not recognized until 1957 when Petuely discovered that it act as a growth factor for Bifidobacteria (Petuely, 1957).

It is more soluble in water than lactose and about half as sweet as sucrose and does not crystallize easily even in concentrated 
solutions. Lactulose is much less stable in solution than lactose and may subsequently degrade via process of $\beta$-elimination to give galactose, tagatose and saccharinic acids and other low molecular weight products (Olano and Martinez-Castro, 1981). Subsequently, lactulose may epimerize via a 2,3-enediol to form epilactose (4-O- $\beta$-D-galactopyranosylD-mannose).It reduces Fehling's solution on heating.

As per Speck (1958) two main pathways should exist since the $\mathrm{pH}$ range of milk systems permits the possibilities of transformation in two ways. The first path is theLobry de Bruyn-Alberda van Ekenstein (LA) transformation. This is in essence an alkaline isomerization. The second theory of the mechanism of lactulose formation assumes the formation of lactosylamine which undergoes Amadori rearrangement to lactulose by hydrolytic degradation.

\section{Formation in Milk during Heat Treatment}

Temperatures above $100^{\circ} \mathrm{C}$ as applied in the production of sterilized and UHT milk enhanced product stability, but also induce several chemical reactions of milk components, such as the isomerization of lactose into lactulose. In the case of lactulose formation, the glucosemoiety of lactose is isomerized into its keto-analogue fructose, a process which is favoured by heat and alkaline conditions. Observed lactulose concentrations vary between $0.3 \mathrm{~g} / \mathrm{l}$ for UHT milk and $1.6 \mathrm{~g} / \mathrm{l}$ for sterilized milk (Mendoza et al., 2005).

Increasing the content of lactulose in milk by extending heating time or temperature is not possible due to a heat-induced drop of $\mathrm{pH}$ and a simultaneous thermal degradation of lactulose.

\section{Production of lactulos Chemical methods}

Industrial production of lactulose is exclusively carried out by chemical isomerization of lactose via the Lobry de Bruyn-Alberda van Ekenstein (LA) rearrangement. Three different methods namely alkalising catalysts, complexing agents and ion-mediated process are employed for lactulose production by chemical methods.

\section{Alkalising catalysts}

Alkaline catalysts like triethylamine, sodium hydroxide, magnesium oxide and sulfites, provoking a $\mathrm{pH}$ of $10-12$ in the reaction mixture, have been successfully employed for the isomerization of lactose (Montgomery and Hudson, 1930). A new group of catalysts was introduced with calcium carbonate-based by-products like egg and oyster shells (Montilla et al., 2004; Villamiel et al., 2002).

\section{Complexing agents}

The employed catalysts are borate and aluminate which form an insoluble complex with ketose sugars like lactulose under alkaline conditions (Hicks and Parrish, 1980; Kozempel and Kurantz, 1994). Zokaee et al. (2002) reported that under similar reaction conditions $\mathrm{Y}_{\text {lactu/lacto }}$ was about $80 \%$ for borate, whereas with aluminate less lactulose was formed (Y $\mathrm{Y}_{\text {lactu/lacto }} 1 / 470 \%$ ) and its degradation was increased (Hicks et al., 1984).

\section{Ion-mediated processes}

Alkalisation of whey was achieved by circulation over strong ion exchange resins activated with hydroxide ions. The exchange of ions like chloride and the subsequent release of hydroxide ions from the resin 
increased the $\mathrm{pH}$ of whey and induced the LA-transformation of lactose into lactulose (Khramtcov et al., 2004). Ion-mediated processes have not been established in industrial processes yet. Evdokimov and Alieva (2004) suggested using the alkaline fraction of electrochemically activated water or lactose solutions obtained by electromembranous methods for the production of lactulose.

\section{Enzymatic Method}

Enzymatic synthesis of lactulose is commonly carried out with classes of enzyme $\beta$-galactosidase and glycosidase. $\beta$ galactosidase is a well-known biocatalyst for transgalactosylation reaction and for the synthesis of lactose based derivatives including galacto-oligosaccharides (Panesar et al., 2006; 2010).

\section{Using free enzymes}

Mayer et al.(2004)reported the production of lactulose by enzymatic transgalactosylation from lactose to fructose by using $\beta$ galactosidase from Aspergillus oryzae and the hyperthermostable $\beta$ - glycosidase from Pyrococcus furiosus.Further, gene encoding a thermostable $\beta$-galactosidase from Sulfolobus solfataricus has been cloned and expressed in Escherichia coli for lactulose production (Kim et al., 2006).Enzymatic synthesis of lactulose from whey permeate was affected by $\beta$-galactosidase preparation, substrate concentration and by theratio of lactose and fructose (Adamczak et al.,2009).

\section{Using immobilized enzymes}

Lactulose has also been successfully synthesized by dual enzymatic consisting of immobilized lactase and immobilized glucose isomerase. Immobilized lactase is prepared by cross-linking the free lactase into $\mathrm{Fe}_{3} \mathrm{O}_{4}{ }^{-}$chitosan magnetic microspheres
(Hua et al., 2010). Mayer et al., (2010) developed a continuous enzymatic process for the production of lactulose through transgalactosylation using free and immobilized $\beta$-glycosidase from Pyrococcus furiosus.

\section{Using whole cells}

Whole cells used as biocatalyst for the production of lactulose often causes very low reaction rates due to permeability barrier of the cell envelope for substrates and products. The permeabilized Kluyveromyces marxianus cells as a source of $\beta$-D-galactosidase were used to overcome this problem. Ethanol permeabilization of yeast cells has been shown to be an economical, easy, convenient and safe (Lee et al., 2004).

\section{Extraction and Purification of Lactulose}

During lactulose production, the reaction mixture is generally not pure, and usually contains appreciable quantities of other substances such as lactose, glucose, galactose, epilactose etc. The recovery of lactulose during downstream processing has been found to be an important reaction because the amount of purified lactose was affected by both physical and chemical treatments. A strong acidification of obtained solution has been carried out at temperature in order to release lactulose and to induce precipitation of borate as boric acid and sodium aluminate as gel like aluminium hydroxide (Kozempel et al., 1995). Moreover, separation steps have been evolved for the removal of borate by the crystallization of boric acid of $50 \%$ in a solution with $20 \%$ (w/w) carbohydrates and $15 \%$ (w/w) borate (Kozempel et al., 1995). But, in case of heterogeneous catalysts (like powdered egg shells), centrifugation method has been used for recovery of lactulose and the obtained sugar solution has been 
decolourized using activated carbon without decreasing the concentration of recovered lactulose (Montilla et al., 2005). The purification of lactulose from a mixture with lactose has also been carried out by using pressurized liquid extraction (PLE) at 1500 psi for $30 \mathrm{~min}$ and the recovery of lactulose reached up to $84.4 \%$ with a purity of over 90\% (Ruiz-Matute et al., 2007).

\section{Analysis}

A range of methodologies have been reported to determine the lactulose including, gas-liquid chromatography (GC), thin-layer chromatography (TLC) and highperformance liquid chromatography (HPLC), capillary electrophoresis, differential $\mathrm{pH}$ methods and flow analysis methods. A high pressure liquid chromatography was also used for the separation of galactose, tagatose, lactose and lactulose with a commercial carbohydrate analysis column (Parrish et al., 1980).

Khan et al., (2006) developed a method based on hydrolysis of lactulose under acidic conditions followed by reaction of the hydrolysed product with resorcinol, giving absorption peaks at 398 and $480 \mathrm{~nm}$. A simple and rapid flow system was developed for the determination of lactulose in milk samples, which is based on the hydrolysis of lactulose to galactose and fructose by the enzyme $\beta$-galactosidase immobilized in a reactor (Moscone et al., 1999).

Amine et al. (2000) developed an enzymatic spectrophotometric assay for the determination of lactulose in milk samples by the hydrolysis of lactulose to fructose and galactose, and fructose dehydrogenase reacts with fructose in presence of a tetrazolium salt giving a coloured compound which can be detected spectrophotometrically at $\mathbf{5 7 0}$ nm.

\section{Physiological Effects of Lactulose}

The $\beta$-glycosidic linkage of the disaccharide lactulose is not hydrolyzed by mammalian digestive enzymes and ingested lactulose passes the stomach and small intestine without degradation. This selective metabolism of lactulose alters the microbial balance and the biochemical composition of caecal contents. Several in-vivo studies have demonstrated that lactulose favours the growth of grampositive cocci and rods mostly belonging to the genera Bifidobacterium and Lactobacillus (Bouhnik et al., 2004), while bacterial counts of galactosidase negative microorganisms like subspecies of the genera Clostridium and Bacteroides have been shown to decrease (Mizota et al., 2002). Lactulose is now a commonly used drug worldwide, and is listed in the US Pharmacopeia, European Pharmacopoeia and Japanese Pharmacopoeia.

\section{Fermentation by colonic bacteria}

Sahota et al., (1982) screened sixty-four bacteria cultured under anaerobic conditions in lactulose containing media to assess their ability to ferment lactulose. Some organisms were unable to metabolize the disaccharide, while others, e.g. clostridia and lactobacilli, metabolized lactulose extensively. Quantitative analyses of the fermentation products indicated that the major nongaseous metabolites were acetic, lactic and butyric acids and hydrogen and carbon dioxide were the only gases detected.

\section{Treatment of constipation and hepatic encephalopathy}

Lactulose is widely established as a laxative agent in the treatment of constipation (Schumann, 2002). Theextent of purgative action depends on various facts, including 
the health status, age, weight, gender and diet of the concerned person. Oku and Okazaki (1998) determined the laxative threshold concentration of lactulose to be $0.26 \mathrm{~g}$ per $\mathrm{kg}$ (body weight) in 20 Japanese females. Assuming an average body weight of $55 \mathrm{~kg}$, a healthy female may consume up to14.3 g lactulose in a single dose without suffering diarrhea. Studies confirmed that lactulose cured the neuropsychiatric symptoms of hepatic encephalopathy, although the mode of its action remained unclear (Schumann, 2002). Minimal hepatic encephalopathy (MHE) could be treated with 30-60 ml lactulose (adult) (approx. 20$40 \mathrm{~g}$ lactulose), thus clearly improving of the health related quality of life of cirrhotic patients (Sharma et al., 2008).

\section{Enhancement of mineral absorption}

The improved absorption of minerals has been generally described for prebiotics and is presumably mediated by an increased permeability of intestinal mucosa and an enhanced solubility of minerals in the colon at low pH (MacFarlane et al., 2006). Studies by Seki et al., (2007) and Van den Heuvel et al. (1999) showed $\mathrm{Ca}$ and $\mathrm{Mg}$ absorption can be improved by lactulose administration.

\section{Prebiotic action}

The prebiotic action of lactulose has been documented throughout the last five decades. According to Bovee-Oudenhoven et al. (2003) lactulose inhibited the colonisation of Salmonella in rats. Lactulose leads to a sharp drop of the colonic $\mathrm{pH}$, which makes Salmonella difficult to survive. Lactulose therapy clears faecal Salmonella and Shigella species and reduces the prevalence of urinary-tract infection and respiratory tract infections (Liao et al., 1994).The application of lactulose as a beneficial, prebiotic nutrient is restricted to low doses as a higher intake would probably cause frequent bowel movements or diarrhea. A survey of studies focussing the dose-response of lactulose indicates that single doses of lactulose exert prebiotic action from a daily intake of 4 to $10 \mathrm{~g}$ in adult (Mizota et al., 2002).

In the work carried out by Oliveira et al. (2011) use of lactulose in fermented milk improved the quality of skim milk fermented by Lactobacillus acidophilus, Lactobacillus rhamnosus, Lactobacillus bulgaricus and Bifidobacterium lactis in co-culture with Streptococcus thermophilus. Compared to control fermentations without lactulose, the addition of such a prebiotic in skim milk increased the counts of all probiotics, with particular concern toB.lactis.

\section{Treatment of colon carcinogenesis}

Lactulose appear to reduce the risk of colon cancer (Schumann, 2002). Challa et al. (1997) investigated the influence of Bifidobacterium longum and lactulose on the chemical induction of aberrant crypt foci (ACF), a precursor of colonic adenoma, in rats. They showed that lactulose decreased the incidence of ACF, a phenomenon that was partly ascribed to the lowering of caecal $\mathrm{pH}$.

\section{Anti-endotoxin effects}

Lactulose treatment before operation can prevent endotoxindependent complications such as renal dysfunction (Özçelik et al., 1997; Pain et al., 1991). The anti-endotoxin effect of lactulose has also important medical applications in metabolic diseases like the hepatorenal syndrome (Kramer, 1988), exocrine pancreatic dysfunction (Mack et al., 1992), diabetes mellitus (Yelich et al., 1992) and hypercholesterolemia (Liao and Florin, 1995). 


\section{Blood glucose and insulin}

Lactulose has also an important application in lowering blood glucose level (Bianchi et al., 1994). Cornell (1985) also suggested that endotoxin reduces the pancreatic insulin production and thus lactulose shows antidiabetic effect.

\section{Tumour prevention and immunology}

Bifidobacteria play an important role in tumour prevention. The antitumour and immunologic effects of Bifidobacteria can be enhanced by intake of lactulose (Schumann, 1997).

\section{Inflammatory bowel disease}

Oral administration of lactulose abolishes and prevents systemic endotoxemia of gut origin. Obstructive jaundice is often accompanied by bacterial translocation and subsequent sepsis and the administration of lactulose may prevent systemic endotoxaemia and the subsequent inflammatory response in an experimental model of obstructive jaundice (Koutelidak et al., 2003). Fermentation of lactulose by gastrointestinal tract bacteria, can produce a considerable amount of mobilized endogenous hydrogen, which is protective for DSS-induced colitis as a unique antioxidant, which can reduce oxidative stress and ameliorate symptoms of inflammatory bowel disease in human beings (Chen et al., 2011).

\section{Applications}

\section{Food Applications}

The use of lactulose as a food ingredient was introduced in 1957 by Petuely (Petuly, 1957) who was the first to favour the growth of the bifidus flora in infants by adding lactulose to diet. Its high thermostability under acidic conditions is considered one of its most advantageous characteristics and allows it to be utilized in acidic foods such as fruit juice. Incorporation of $0.5 \%$ lactulose in the infant formula is considered adequate to stimulate Bifidobacteria flora to the extent observed in breast-fed babies, while the presence of lactulose at $1 \%$ level in the formula may also provide laxative effect (Nagendra et al., 1995). Adriana et al. (2002) found that lactulose contents of infant formulas containing lactose were between 29 and $108 \mathrm{mg} / \mathrm{l}$ of reconstituted formulas based on milk and 97 and $312 \mathrm{mg} / \mathrm{l}$ of reconstituted formulas based on milk enriched with whey. Although no limit to lactulose content in infant formulas has been established, the lactulose contents in these formulas were well below this limit suggested by IDF (1992) and EU commission (1992) for commercial UHT milk. The addition of lactulose reduced the incubation period in the manufacture of bioyogurt containing Lactobacillus acidophilus and Bifidobacterium bifidum and caused a significant increase in the cell counts of B.bifidum during cold storage $\left(<6^{\circ} \mathrm{C}, 14\right.$ days) (Ozer et al., 2005).Pham and Shah (2008) observed that the addition of $0.5 \%$ $(\mathrm{w} / \mathrm{v})$ of lactulose to soy milk appeared to favour the growth of $B$. longum and $B$. Animalis which in turn enables transformation of isoflavone glycosides to biologically active isoflavone aglycones.

\section{An Indicator for Heat Treated Milk}

Assuming that only minimal lactulose degradation occurs within traditional milk heating, lactulose can be used to characterize the heat load and to distinguish between differently processed batches of milk. Concentration of lactulose in sterilized milk differs significantly from UHT milk, which itself can be assigned to either direct or indirect heating by the amount of formed 
lactulose (Olano et al., 1989). Lactulose was proposed by the International Dairy Federation (IDF) and the European Union (EU) as a parameter capable of differentiating between UHT milk and incontainer sterilized milk (EU Commission, 1992; IDF, 1992, 1993) with $600 \mathrm{mg} / \mathrm{l}$ of lactulose as a marker for distinguishing between two milk types.

With regard to pasteurized, microfiltered and pasteurised, high temperature pasteurized milk and reconstituted powered milk, upper limits (threshold) of lactulose concentration cannot be proposed since the methods available for lactulose determination are neither sufficiently sensitive (level of detection 50mg/l) (Moscone et al., 1999). Marconi et al. (2004) derived a sensitive enzymatic assay method to distinguish lactulose content, not only in-container sterilized milk, indirect and direct UHT, but also UHT milk produced by mild technologies such as milk treated by infusion, high temperature pasteurized milk and low temperature pasteurized milk. Cho et al. (2012) reported that lactulose and furosine concentration ratio is a suitable milk quality indicators of heat damage and for demonstrating improper addition of reconstituted milk powder.

\section{Diagnostic Applications}

Lactulose is applied in the diagnosis of colonic disorders by means of the breath hydrogen test. This test consists of the oral administration of a single dose of lactulose and the determination of exhaled hydrogen formed by means of bacterial metabolism of lactulose in the intestine. The amount and the time of hydrogen production and exhalation conclude the colonic transit time and microbial colonization (Simren and Stotzer, 2006). The lactulose breath test is also applied for the diagnosis of bacterial overgrowth in the small intestine (Nucera $e t$ al., 2005).

\section{Safety and Regulatory Status}

European Food Safety Authority (2010) released a "scientific opinion on the substantiation of health claims related to lactulose and decreasing potentially pathogenic gastro-intestinal microorganisms (ID 806) and reduction in intestinal transit time (ID 807)". The European chemical Substances Information System (ESIS) provides a detailed description of chemical and pharmacological properties of lactulose. Included data on the acute oral toxicity of commercial lactulose preparations summarize various animal studies with values for the median lethal dose $\mathrm{LD}_{50}$ ranging from 25 to $65 \mathrm{~g}$ per $\mathrm{kg}$ body weight. Drugbank, a Canadian database operated by the University of Alberta additionally specifies that pure lactulose could provoke slight irritations in case of skin or eye contact. According to the Anatomical Therapeutical Chemical Classification System for pharmaceutical drugs established by the World Health Organization, lactulose is an osmotically acting laxative substance (ATC Code ATC06AD11). For this purpose the recommended administration of lactulose, expressed as the defined daily dose (DDD) is indicated with $6.7 \mathrm{~g}$. But apart from its status as a pharmaceutical drug, lactulose is regarded as a functional food additive. The Japanese Ministry of Health and Welfare has acknowledged the nutritional benefits of lactulose by including it in the list of functional foods with the official label FOSHU (Food of Specified Health Use). In the European Union, the labelling of food containing lactulosewith thehealthrelated claims "prebiotic" and "lowers colonic transit time" has been proposed for products with a minimum dose of $2.5 \mathrm{~g}$ lactulose. 
In conclusion, lactulose is a disaccharides and produced by the isomerization of lactose. Lactulose can be generated by either alkaline isomerization, enzyme-catalyzed synthesis or by membrane technology. Lactulose can be used as an indicator of heat treatments. The physiological action of lactulose has been focussed by clinical trials for over five decades, leading to its application as pharmaceutical as well as a prebiotic food ingredient.

\section{References}

Adamczak, M., Charubin, D. and Bednarski, W. (2009). Influence of reaction medium composition on enzymatic synthesis of galactooligosaccharides and lactulose from lactoseconcentrates prepared from whey permeate. Chem Pap. 6:111-6.

Adriana, S. P., Gabrieala, B. N., Laura, S.M. and Maria, S.V. (2002). Available lysine, protein digestibility and lactulose in commercial infant formulas. Int. Dairy J., 13:95-99.

Amine, A., Moscone, D., Palleschi, G. 2000. Rapid determination of lactulose in milk using Seliwanoff's reaction. Anal Lett. 33:125-35.

Bianchi, G.P., De Mitri, M.S., Bugianesi, E., Abbiati, R., Fabbri, A. and Marchesini, G. (1994). Lowering effects of a preparation containing fibres and lactulose on glucose and insulin levels in obesity. Ital $J$ Gastroenterol. 26:174-8.

Bouhnik, Y., Attar, A., Joly, F. A., Riottot, M., Dyard, F. and Flourié, B. 2004. Lactulose ingestion increases faecal bifidobacterial counts: a randomised double-blind study in healthy humans. Eur J. Clin. Nutr., 58. 16581664.

Bovee-Oudenhoven, I.M.J., ten Bruggencate, S.J.M., Lettink-
Wissink, M. L. G. and van der Meer, R. 2003. Dietary fructooligosaccharides and lactulose inhibit intestinal colonisation but stimulate translocation of salmonella in rats. Gut. 52.1572-1578.

Challa, A., Rao, D. R., Chawan, C. B. and Shackelford, L. 1997. Bifidobacterium longum and lactulose suppress azoxymethane-induced colonic aberrant crypt foci in rats. Carcinogenesis. 18. 517-521.

Chen, X., Zuo, Q., Hai, Y. and Sun, X.J. 2011. Lactulose: an indirect antioxidant ameliorating inflammatory bowel disease by increasing hydrogen production. Med Hypotheses. 76:325-7.

Cho, Y.H., Hong, S.M. and Kim, C.H. 2012. Determination of lactulose and furosine formation in heated milk as a milk quality indicator. Korean J Food Sci An. 32(5):540-544.

Claeys, W. L., Ludikhuyze, L. R. and Hendrickx, M. E. 2001. Formation kinetics of hydroxymethylfurfural, lactulose and furosine in milk heated under isothermal and non-isothermal conditions. J Dairy Res. 68: 287-301.

Cornell, R.P. 1985. Endogenous gut-derived bacterial endotoxin tonically primes pancreatic secretion of insulin in normal rats. Diabetes. 34:1253-9.

EU Commission. 1992. Dairy chemist group Doc. VI/5726/92. Rev.2. Proposal of the commission.

Evdokimov I. A. and Alieva L. R. 2004. Membrane fractionation for the production of lactuloseBulletin of the International Dairy Federation 389. Brussels .

Gaenzle, M. G., Haase, G. and Jelen, P. 2008. Lactose: crystallization, hydrolysis abd value-added derivatives. Int Dairy J. 18:685-694. 
Hicks, K. B. and Parrish, F. W. 1980. A new method for the preparation of lactulose from lactose. Carbohydrate Research. 82: 393-397.

Hicks, K. B., Raupp, D. L. and Smith, P. W. 1984. Preparation and purification of lactulose from sweet cheese whey ultrafiltrate. J Agri Food Chem. 32: 288-292.

Hua, X., Yang, R., Zhang, W., Fei, Y., Jin, Z. and Jiang, B. 2010. Dualenzymatic synthesis of lactulose in organic-aqueous two-phase media. Food Res Int. 43:716-22.

IDF. 1992. Influence of technology on the quality of heat treated milk and fluid milk products. Bulletin of the International Dairy Federation (BDoc. 222. Brussels.

IDF. 1993. Influence of technology on the quality of heat treated milk and fluid milk products. Bulletin of the International Dairy Federation (BDoc. 235. Brussels.

Khan, M.A., Iqbal, Z., Jan, M.R., Shah, J., Ahmad, W., Haq, Z.U. and Obaidullah. 2006. A spectrophotometric method for quantitative determination of lactulose in pharmaceutical preparations. J Anal Chem. 61:32-6.

Khramtcov, A. G., Ryabtceva, S. A., Evdokimov, I. A., Serov, A. V., Evdokimova, L. I. and Lodygina, S. V. 2004. The receiving of lactulosesyrup with the use of anionexchange gums. Retrieved 26.08.09 from http://www.ncstu.info/index-en.php3? path $1 / 4 \_s c i e n c e /$ trudi/food\&source $1 / 47$ (in Russian.

Kim, Y.S., Parkand, C.S. and Oh, D.K. 2006. Lactulose production from lactose and fructose by a thermostable $\beta$-galactosidase from Sulfolobus solfataricus. Enzyme Microb Technol.39:903-8.
Koutelidak, I., Papaziogas, B., GiamarellosBourboulis, E.J., Makris, J., Giamarellou, P.H. and Papaziogas, T. 2003. Systemic endotoxaemia following obstructive jaundice: the role lactulose. J Surg Res. 113:243-7.

Kozempel, M. and Kurantz, M. 1994. The isomerization kinetics of lactose to lactulose in the presence of borate. $J$ Chem Tech Biotech. 59: 25-29.

Kozempel, M.L., Kurantz, M.J., Craig, J.C. and Hicks, K.B. 1995. Development of continuous lactulose process: separation purification. Biotechnol prog. 11:592-5

Kramer, H.J. 1988. Therapie des hepatorenalen syndromes. Deut med Wschr. 113: 561-4.

Lee, Y. L., Kim, C.S. and Oh, D.K. 2004. Lactulose production by $\beta$ galactosidase in permeabilized cells of Kluyveromyces lactic. Applied Microbiol Biotechnol.64: 787-793

Liao, W. and Florin, C.H. 1995. Endotoxin, cytokines and hyperlipidemia. Scand J Gastroenterol. 28:97-103.

Liao, W., Cui, X.S., Jin, X.Y. and Florén, C.H. 1994. Lactulose-a potential drug for the treatment of inflammatory bowel disease. Med Hypotheses. 43:234-8.

MacFarlane, S., MacFarlane, G. T. and Cummings, J. H. 2006. Prebiotics in the gastrointestinal tract. Alimentary Pharmacology Therapeutics. 24:701714.

Mack, D.R., Flick, J.A., Durie, P.R., Rosentein, B.J., Ellis, L.E. and Perman, J. A. 1992. Correlation of intestinal lactulose permeability with exocrine pancreatic dysfunction. $J$ Pediatr. 120:696-701.

Marconi, E., Messia, M.C.., Amine, A., Moscone, D., Vernazza, F., Stocchi, F. and Palleschi, G. 2004. Heat treated milk differentiation by a 
sensitive lactulose assay. Food chem. 84: 447-450.

Mayer, J., Conrad, J., Klaiber, I., Lutz-Wahl, S., Beifuss, U. and Fischer, L. 2004. Enzymatic production andcomplete nuclear magnetic resonance assignment of the sugar lactulose. $J$ Agric Food Chem .52:6983-90.

Mayer, L., Kranz, B. and Fischer, L. 2010. Continuous production of lactulose by immobilized thermostable $\beta$ glycosidase from Pyrococcus furiosus. J Biotechnol .145:387-93.

Mendoza, M. R., Olano, A. and Villamiel, M. 2005. Chemical indicators of heat treatment in fortified and special milks. J Agri Food Chem. 53: 29952999.

Mizota, T., Mori, T., Yaeshima, T., Yanagida, T., Iwatsuki, M. and Ishibashi, N. 2002. Effects of low dosages of lactulose on the intestinal function of healthy adults. Milchwissenschaft. 57: 312-315.

Montgomery, E. M. and Hudson, C. S. 1930. Relations between rotatory power and structure in the sugar group. XXVII. Synthesis of a new disaccharide ketose (lactulose) from lactose. $J \mathrm{Am}$ Chem Soc. 52: 2101-2106.

Montilla, A., Castillo, M.D., Sanz, M.L. and Olano, A. 2004. Egg shell as catalyst of lactose isomerisation to lactulose. Food Chem.90:883-90.

Montilla, A., Castillo, M.D., Sanz, M.L. and Olano, A. 2005. Egg shell as catalyst of lactose isomerisation to lactulose. Food Chem. 90:883-90.

Moscone, D., Bernardo, R.A., Marconi, E., Amine, A. and Palleschi, G. 1999. Rapid determination of lactulose in milk by microdialysis and biosensors. Analyst. 124:325-9.

Nagendra, R.,Viswanatha, S., Kumar, S.A., Murthy, B.K. and Rao, S.V.(1995. Effect of feeding milk formula containing lactulose to infants on fecal bifidobacteria flora. Nutr Res. $15: 15-2$

Nucera, G., Gabrielli, M., Lupascu, A., Lauritano, E.C., Santoliquido, A., Cremonini, F., Cammarota, G., Tondi, P., Pola, P., Gasbarrini, G. and Gasbarrini, A. 2005. Abnormal breath tests to lactose, fructose and sorbitol in irritable bowel syndrome may be explained by small intestinal bacterial overgrowth. Aliment Pharmacol Ther. 21:1391-5.

Oku, T. and Okazaki, M. 1998. Transitory threshold of trehalose and lactulose in healthy woman. J. Nutr Sci and Vitaminolo. 44: 787-798.

Olano, A. and Martinez-Castro, I. 1981. Formation of lactulose and epilactose from lactose in basic media. A quantitative study. Milchwissenschaft. 36: 533-536.

Olano, A., Calvo, M. M., and Corzo, N. 1989. Changes in the carbohydrate fraction of milk during heating processes. Food Chemistry. 31: 259265.

Oliveira, R.P., Florence, A.C., perego, P., Oliveira, M.N. and Converti, A. 2011. Use of lactulose as prebiotics and its influence on the growth, acidification profile and viable count of different probiotics in fermented skim milk. Int j food microbio. 145:22-27.

Özçelik, M.F., Pekmezci, S., Altinli, E., Eroglu, C., Göksel, S. and Göksoy, E. 1997. Lactulose to prevent translocation in biliary obstruction. Dig Surg. 14:267-71.

Ozer, D., Akin, S. and Ozer, B. 2005. Effect of inulin and lactulose on survival of Lactobacillus acidophilus and Bifidobacterium bifidum BB-02 I Acidophilus-Bifidus yoghurt. Food Sci Technol int.11:19-24. 
Pain, J.A., Cahill, C.J., Gilbert, J.M., Johnson, C.D., Trapnell, J.E. and Bailey, M.E. 1991. Prevention of postoperative dysfunction in patients with obstructive jaundice: a multicentre study of bile salts and lactulose. Br J Surg.78:467-9.

Panesar, P.S., Kumari, S. and Panesar, R. 2010. Potential applications of immobilized $\beta$-galactosidase in food processing industries. Enzyme Res :116.

Panesar, P.S., Panesar, R., Singh, R.S., Kennedy, J.F. and Kumar, H. 2006. Microbial production, immobilization and applications of $\beta$-Dgalactosidase. $J$ Chem Technol Biotechnol. 81:530-43.

Parrish, F.W., Hicks, K. and Doner, L. 1980. Analysis of lactulose preparations by spectrophotometric and high performance liquid chromatographic methods. J Dairy Sci. 63: 1809-14.

Petuely, F. 1957. Der Bifidusfaktor. Deutsche Medizinische

Wochenschrift, 82: 1957-1960, (In German.

Pham, T.T. and Shah, N.P. 2008. Effect of lactulose on biotransformation of isoflavone glycosides to aglycones in soymilk by Lactobacilli. $J$ Food Sci.73:158-165.

Ruiz-Matute, A.L., Sanz, M.L., Corzo, N., Martin-Alvarez, P.J., Ibanez, E., Martinez-Castro, I. and Olano, A. 2007. Purification of lactulose frommixtureswith lactose using pressurized liquid extraction with ethanol-water at different temperatures. $J$ Agric Food Chem.55:3346-50.

Sahota, S.S., Bramley, P.M. and Menzies, I.S. 1982. The fermentation of lactulose by colonic bacteria. J.General Microbio. 128:319-325.
Schumann, C. 1997. Die immunologischen Effekte der Lactulose. Notabene medici. 27:288-90.

Schumann, C. 2002. Medical, nutritional and technological properties of lactulose. An update. Eur J Nutr. 41:17-25.

Seki, N., Hamano, H., Iiyama, Y., Asano, Y., Kokubo, S. and Yamauchi, K. 2007. Effect of lactulose on calcium and magnesium absorption: a study using stable isotopes in adult men. $J$. Nutri. Sci. Vitaminolo.53: 5-12.

Sharma, P., Sharma, B. C., Puri, V., and Sarin, S. K. 2008. An open-label randomized controlled trial of lactulose and probiotics in the treatment of minimal hepatic encephalopathy. Eur. J. Gastroenterolo. Hepatolo.20: 506511.

Simren, M. and Stotzer, P.O. 2006. Use and abuse of hydrogen breath tests. Gut. 55:291-303.

Speck, J. C. 1958. The Lobry de BruynAlberda van Ekenstelu Transformation. Adv Carbohydrate Chem. 13: 63.

Van den Heuvel, E. G. H. M., Muijs, T., Van Dokkum, W. and Schaafsma, G. 1999. Lactulose stimulates calcium absorption in postmenopausal women. J. Bone and Mineral Res.14: 1211-1216.

Villamiel, M., Corzo, N., Foda, M. I., Montes, F. and Olano, A. 2002. Lactulose formation catalysed by alkaline-substituted sepiolites in milk permeate. Food Chem.76:7-11.

Yelich, M.R., Schieber, C.K., Umporowicz, D.M. and Filkins, J.R. 1992. Polymyxin-B suppresses endotoxin induced insulin hypersecretion in pancreatic islets. Circ Shock. 38:8590. 
Zokaee, F., kaghazchi, T., Zare, A. And Solemani, M. 2002. Isomerization of lactose to lactulose- study and comparison of three catalytic systems. Process Biochem. 37: 629-635.

\section{How to cite this article:}

Sonali L. Parekh, Smitha Balakrishnan, Subrota Hati and K.D. Aparnathi. 2016. Lactulose: Significance in Milk and Milk Products. Int.J.Curr.Microbiol.App.Sci. 5(11): 721-732. doi: http://dx.doi.org/10.20546/ijcmas.2016.511.083 